\title{
Thematic issue: Bioenergy and biorefinery approaches for environmental sustainability
}

\author{
K. Haribabu ${ }^{1} \cdot$ V. Sivasubramanian ${ }^{1} \cdot$ B. Deepanraj ${ }^{2} \cdot$ Hwai Chyuan Ong $^{3}$ \\ Published online: 7 October 2021 \\ (c) The Author(s), under exclusive licence to Springer-Verlag GmbH Germany, part of Springer Nature 2021
}

Environmental sustainability is concerned with our collective responsibility to minimize depletion and deterioration of environmental assets and to support long-time stable ecosystems. Additionally, achieving true sustainability demands that we find a balance between economic development and environmental protection to fulfill the needs of current and future generations. In this respect, ending the severe deterioration of non-renewable resources caused by a sophisticated living environment, combined with a rapidly increasing population, is critical for society and for future generations. Thus, innovative solutions are needed to prevent climate change, including minimizing the use of non-renewable fossil fuels.

Against this overall framing, the substitution of fossil fuel energy with renewable resources of energy such as biomass and its resultant organic waste has been developing more and more as an attractive alternative - driving, additionally, the development of biorefinery systems. These renewable energies will be essential contributions to ensuring global energy security, while also reducing the need for fossil fuel and cutting greenhouse gas emissions. This "green" energy is promising for the environment since it avoids negative effects of the use of fossil fuel energy. Additionally, the use of bioenergy is a viable alternative to fossil fuel energy in areas such as heat supply, and for transportation purposes. Further reasons to support bioenergy are the contributions it would make towards achieving a higher degree of energy security, and the creation of new employment, especially in rural areas.

B. Deepanraj

babudeepan@gmail.com; deepanrajb@jecc.ac.in

1 Department of Chemical Engineering, National Institute of Technology Calicut, Kozhikode, India

2 Department of Mechanical Engineering, Jyothi Engineering College, Thrissur, India

3 Centre for Green Technology, Faculty of Engineering and Information Technology, University of Technology Sydney, Ultimo, Australia
The International Conference on Green Energy for Environmental Sustainability (ICGEES 2020) is an endeavor to gather concerned professionals to discuss the aspects of green energy for environmental sustainability and to seek solutions wherever possible. The scope of the gathering extends to sustainable biofuels, bionanomaterials and applications, bioenergy policy, biological separation techniques, biorenewable polymers, chemical and biochemical processes, waste biorefineries, biological resources and chemical processes, biomass products for new renewable sources of energy, economic aspects of biomass, environmental management, and bioenergy conversions. The papers presented at this conference were chosen for their scientific rigor and quality to be submitted as a full paper to Biomass Conversion and Biorefinery. This thematic issue contains these papers - approved additionally by the journal's peer-review process.

This thematic issue "Bioenergy and Biorefinery Approaches for Environmental Sustainability" presents therefore articles related to green energy, the use of biomass residues through advanced processes considering system sustainability, bioenergy processes, the energy proficiency of bioenergy systems, bioenergy utilization, biodiversity, and valuation of sustainability, among other topics. The thematic issue contains highquality research on all other areas of the environment and green energy, including biofuel, energy storage, bioenergy and catalysis for sustainable processes, energy and environmental materials. All papers contained within this issue demonstrate significant improvements and scientific accomplishments; nevertheless, despite these numerous advancements, the field still needs further research. These scientific publications provide a wide collection of new views and innovative ideas.

We want to express our gratitude to the authors as well as the reviewer for their great engagement to compile this comprehensive thematic issue.

Publisher's Note Springer Nature remains neutral with regard to jurisdictional claims in published maps and institutional affiliations. 